\title{
Pierre Bayle
}

und die

"Nouvelles de la République des Lettres".

(1684-1687.) 



\section{NOUVELLES}

D E L A

\section{REPUBLIQUE}

D E S

\section{E T T R E S.}

Mois de Mars $168,$.

Par le Sicur B.... Profeficur en Ihilolophie \& en Hiftoire à Rotterciam.

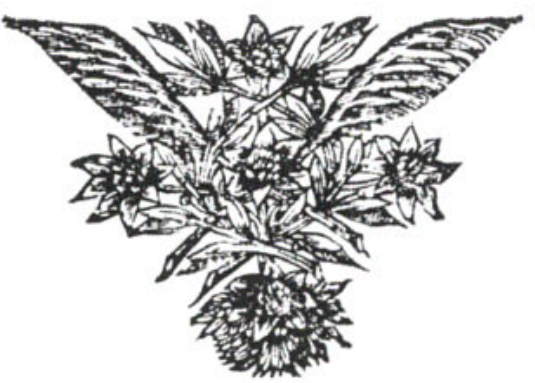

A A M T T R A M,

Chez HENRY DESBORDES, dans le Kalver-Straat, prés le Dam.

1. DC. IXXXV.

Aver Irivilege des Etats de Holl. G Tretsf. 



\title{
Pierre Bayle
}

und die

\section{"Nouvelles de la République des Leettres“}

(Erste populärwissenschaftliche Zeitschrift)

$1684-1687$

\section{Von \\ Louis P. Betz}

Dr. phil.

Mit einem Facsimile des Titelblattes der Zeitschrift

\author{
$\mathrm{ZÜRICH}$
}

Albert Müllers Verlag 
Alle Kechte vorbelalten.

Druck von J. Schabelitz in Züriè. 
elleiner ellutter. 

„Mag man den französischen Philosophen des vorigen Jahrhunderts seichte Aufklärerei vorwerfen so viel man will, man wird ihnen den Ruhm nicht streitig machen können, dass sie für die höchsten Güter der Menschheit, für persönliche Freiheit und humane Entwicklung im Völkerleben mit Kraft und Begeisterung eingetreten sind. Wenn man sie aber nennt, darf man Bayle nicht vergessen." Fierd. Isotheissen.

„Ji: ne crois pas qu'il y ait, dans toute l'histoire de notre littérature, un exemple plus singulier de l'ingratitude ou de l'injustice de la postérité que celui de Pierre Bayle."

F. Brunetière.

"Tout est dans Bayle, mais il faut l'en tirer."

Sainte-Beure. 
